WellBeing International

WBI Studies Repository

$11-2005$

\title{
In Situ Examination of Boldness-Shyness Traits in the Tropical Poeciliid, Brachyraphis episcopi
}

\author{
Culum Brown \\ University of Edinburgh \\ Felicity Jones \\ University of Edinburgh \\ Victoria Braithwaite \\ University of Edinburgh
}

Follow this and additional works at: https://www.wellbeingintlstudiesrepository.org/acwp_asie

Part of the Animal Studies Commons, Comparative Psychology Commons, and the Other Animal Sciences Commons

\section{Recommended Citation}

Brown, C., Jones, F., \& Braithwaite, V. (2005). In situ examination of boldness-shyness traits in the tropical poeciliid, Brachyraphis episcopi. Animal Behaviour, 70(5), 1003-1009.

This material is brought to you for free and open access by WellBeing International. It has been accepted for inclusion by an authorized administrator of the WBI Studies Repository. For more information, please contact wbisr-info@wellbeingintl.org.

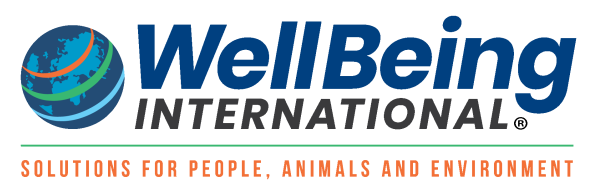




\title{
In Situ Examination of Boldness-Shyness Traits in the Tropical Poeciliid, Brachyraphis episcopi
}

\author{
Culum Brown, Felicity Jones \& Victoria Braithwaite \\ University of Edinburgh
}

\begin{abstract}
Explaining consistent variation in the behaviour of individuals in terms of personality differences is one of the cornerstones of understanding human behaviour but is seldom discussed in behavioural ecology for fear of invoking anthropomorphism. Recently, however, interest has begun to focus on identifying personality traits in animals and examining their possible evolutionary consequences. One major axis used to define personality traits is the shyness-boldness continuum. We examined boldness in an in situ experiment using fish from eight populations of the poeciliid Brachyraphis episcopi (also referred to as Brachyrhaphis episcopi). Fish from high- and low-predation regions within four streams that run independently into the Panama Canal were tested. Boldness scores were strongly influenced by standard length and the relative level of predation pressure in the rivers. In all four rivers, fish from high-predation areas were bolder than those from low-predation areas. Fish became increasingly shy as they grew.
\end{abstract}

Animals are expected to titrate energy intake closely with predation risk and hundreds of studies support this notion (reviewed in Lima 1998). For example, when a risky patch had four times the amount of food available than a low-risk patch, fish accepted the higher risk in return for a higher foraging reward (Pitcher et al. 1988). Not all individuals in a population solve the problem in the same way, however. In laboratory assays of foraging behaviour under predation risk, there is a continuum of responses within a population of prey species, from complete recklessness to complete predator avoidance (Fraser \& Huntingford 1986). These behavioural extremes correspond closely to the shyness-boldness spectrum, recognizable psychological states that exist in a diverse suite of taxa, from crustaceans to humans (Wilson et al. 1994; Gosling 2001). Although many studies have concentrated on the heritability of individual differences in temperament (Goddard \& Bilharz 1985), this range of responses is also determined by life experiences (van Gestel \& van Broeckhoven 2003), and, as such, should be influenced by environmental variables during ontogeny. While the two mechanisms are by no means mutually exclusive, the manner in which the environment shapes and maintains shyness-boldness traits over both evolutionary and ontogenetic timeframes has received little attention from behavioural ecologists.

Comparative analyses are frequently used to address potential differences in animal behaviour caused by variable exposure to selection pressures that result from the occupation of different environments (Kamil \& Balda 1990). Testing populations of the same species that occupy different habitats allows us to examine how the environment affects the determination of personality traits while minimizing the possible confounds of phylogeny. 
Geographical variation in predation pressure is known to affect all manner of traits in prey animals, from physiology to behaviour (Endler 1995), the outcome of which results in a cascade of behavioural and ecological consequences (Sih 1980; Godin \& Smith 1988; Werner \& Anholt 1993; Budaev 1997). When prey species are forced into hiding by predators they are confronted with a dilemma: the longer they stay hidden the lower the chance that the predator is still present, but the greater the energetic costs from lost foraging opportunities. The decision when to emerge from shelter can be influenced by a number of demographic factors including age and sex, environmental factors such as the level of predation pressure and internal states including hunger (Krause et al. 1998). Variation in personality traits is expected to cut across behavioural variation caused by demography, although each demographic category may show consistent differences along the shyness-boldness continuum (Sih et al. 2004). Age or size in particular is likely to have a substantial impact on personality traits in animals since many aspects of how an animal interacts with its environment change as it grows (e.g. microhabitat choice, diet, predation pressure). Furthermore, as animals age they have increasing experience with the environment and have either altered their behaviour to suit (behavioural plasticity) or have been eliminated from the population (selective mortality). Laboratory studies have revealed a strong relation between boldness and body size (Brown \& Braithwaite 2004) but this has never been verified in field studies. Differences between the sexes will also have substantial impacts on personality, not least because males and females often have different life history priorities (Jennions \& Telford 2002).

While controlled laboratory studies can provide useful insights, they are often highly contrived and assume that the behaviour of the animal in captivity will be similar to that in its natural environment. Owing to the constraints of working in the laboratory, experiments investigating boldness have been somewhat artificial and few have attempted to investigate personality traits in wild populations (see Wilson et al. 1993 for an exception). Habitat variables known to affect the perception of risk, such as food availability, predation pressure and distance to cover (Lima \& Dill 1990), are generally controlled because recreating realistic environmental conditions in the laboratory is problematic. How then does an animal apply experiences from its previous habitat to the contrived habitat in which it is tested? Furthermore, because boldness-shyness traits are relatively flexible (Sih et al. 2004), moving animals from the wild and settling them into laboratory conditions may cause behavioural convergence (Wilson et al. 1993, 1994). How do we relate the results of laboratory studies to what is going on under natural conditions? Our previous attempt to study personality traits by bringing the animals into the laboratory yielded variable results, because there might have been differential responses to handling stress and life in captivity (Brown \& Braithwaite 2004). Thus, if we are to understand fully the role of the environment in shaping animal personalities it is critical that we carry out such experiments under natural conditions. We measured the boldness of fish in situ in four rivers each containing a high- and low-predation site. Boldness was determined by the time fish took to emerge from a black, plastic chamber into their home pools. This behaviour is known to be highly correlated with other tests of boldness including the tendency to leave shoalmates and approach novel objects (C. Brown, unpublished data) and is easy to carry out under field conditions.

We addressed three specific questions with this experiment. (1) With respect to the relation between boldness and standard length, we predicted two possible scenarios. The predation pressure hypothesis poses that because juveniles are more prone to predation than adults (reviewed in Sogard 1997) they ought to be more cautious when emerging from shelter. Hence, we predicted a positive relation between standard length and boldness. Such a relation ought to vary between sites of high- and low-predation pressure (i.e. there should be an interaction between predation pressure and size). An alternative hypothesis, the metabolic hypothesis, poses that given that smaller fish have relatively higher metabolic rates, fewer energy reserves and higher drag coefficients (Wootton 1994; Krause et al. 1998; Skalski \& Gilliam 2002) they should be compelled to emerge from cover sooner than larger fish in order to begin 
foraging. This hypothesis predicts the exact opposite relation between standard length and boldness and there ought to be no difference in the relation in fish from high- and low-predation sites. Variation in boldness in relation to standard length is interesting in its own right, but it also provides a potential confound if fish from each site differ in standard length. We therefore controlled for standard length. (2) The second prediction related to the hypothesis that predator-sympatric and predator-allopatric populations may vary in their boldness scores. Specifically, predator-sympatric populations would be more cautious and emerge from shelter later than fish from predator-allopatric populations. (3) Finally, we predicted that males ought to be bolder than females since in many species of freshwater fish females tend to be more risk sensitive than males (guppies, Poecilia reticulata: Griffiths \& Magurran 1998; minnows, Phoxinus phoxinus: Magurran 1986; rainbowfish, Melanotaenia spp.: Brown 2000).

\section{Methods}

We quantified the boldness of eight populations of the poeciliid Brachyraphis episcopi (also referred to as Brachyrhaphis episcopi from four independent rivers along the Panama Canal in the field during the dry season of 2003. Within each of the rivers we selected two sample sites, one with high and one with low predator abundance (see Table 1 for GPS references). The low-predation sites were all located above substantial waterfalls that limit upstream movement of most fish species. The high-predation sites below the falls are known to contain many potential predatory species (table 1 in Brown \& Braithwaite 2004). All the fish in a given pool were captured with small dip nets and stored in dark 20-litre buckets. The fish in these streams are very inquisitive and virtually swim into the net when it is placed in a pool. The netting procedure, therefore, is not particularly stressful. All B. episcopi over $1.5 \mathrm{~cm}$ were sexed and their standard length recorded before being individually placed in a single container for 15 min immediately prior to testing.

Table 1. The coordinates at each of the locations, percentage of $B$. episcopi and potential predators and sex ratios

\begin{tabular}{|c|c|c|c|c|c|}
\hline Site & Coordinates & $\%$ B. episcopi & $\begin{array}{c}\% \\
\text { Predators }\end{array}$ & $\begin{array}{l}\text { Sex ratio } \\
\text { (M:F) }\end{array}$ & $\begin{array}{l}\text { No. of females } \\
\quad \text { (total N) }\end{array}$ \\
\hline \multicolumn{6}{|c|}{ Quebrada Juan Grade } \\
\hline High predation & $79^{\circ} 43^{\prime} 00 / \mathrm{W}, 9^{\circ} 08^{\prime} 37 / \mathrm{N}$ & 27.8 & 66.7 & $1: 4.818$ & $30(40)$ \\
\hline Low predation & $79^{\circ} 42^{\prime} 57 \mathrm{~N}, 9^{\circ} 08^{\prime} 37 / \mathrm{N}$ & 87.9 & 3.8 & 1:9.111 & $29(38)$ \\
\hline \multicolumn{6}{|l|}{ Aqua Salud } \\
\hline High predation & $79^{\circ} 46^{\prime} 49 / \mathrm{W}, 9^{\circ} 12^{\prime} 49 / \mathrm{N}$ & 70.4 & 29.6 & $1: 6.923$ & $31(44)$ \\
\hline Low predation & $79^{\circ} 46^{\prime} 48 / \mathrm{W}, 9^{\circ} 12^{\prime} 52 / \mathrm{N}$ & 97.7 & 0.0 & $1: 30.500$ & $30(33)$ \\
\hline \multicolumn{6}{|l|}{ Rio Limbo } \\
\hline High predation & $79^{\circ} 44^{\prime} 25 / \mathrm{W}, 9^{\circ} 09^{\prime} 38 / \mathrm{N}$ & 7.5 & 79.1 & $1: 5.636$ & $25(35)$ \\
\hline Low predation & $79^{\circ} 44^{\prime} 28 / \mathrm{W}, 9^{\circ} 09^{\prime} 54 / \mathrm{N}$ & 85.6 & 0.0 & 1:14.500 & $22(26)$ \\
\hline \multicolumn{6}{|l|}{ River Macho } \\
\hline High predation & $79^{\circ} 45^{\prime} 42 / \mathrm{W}, 9^{\circ} 11^{\prime} 02 / \mathrm{N}$ & 24.0 & 72.7 & $1: 4.667$ & $24(36)$ \\
\hline Low predation & $79^{\circ} 45^{\prime} 36 / \mathrm{W}, 9^{\circ} 11^{\prime} 02 / \mathrm{N}$ & 38.1 & 0.0 & 1:2.188 & $30(38)$ \\
\hline
\end{tabular}

To test for boldness, we gently poured each fish from the holding container into a small dark plastic box $(8 \times 10 \mathrm{~cm}$ and $19 \mathrm{~cm}$ high) with an opaque lid placed on top where they remained for $2 \mathrm{~min}$. Only one 
fish was tested at a time. The box was positioned in approximately $5 \mathrm{~cm}$ of water on the edge of the pool from which the individuals were collected. Underneath the box a white plastic sheet in the form of a D provided a strong background contrast to the colour of the fish and the substrate. The D served both to aid our ability to track the fish's movement and to represent a potentially dangerous background for the fish to cross. We used a permanent pen to mark a black arc on the white $D$ in a radius of approximately 5 $\mathrm{cm}$ from the trapdoor (Fig. 1). After 2 min settling time, the trapdoor $(5 \mathrm{~cm}$ wide and $10 \mathrm{~cm}$ high) was opened at the front of the box and the fish were free to emerge, travel across the $D$ and into the pool. We recorded both the time taken to emerge from the box after we opened the trapdoor and the time to cross the black arc. If the fish had not emerged from the box after 6 min we removed the lid, thus reducing the value of the refuge and encouraging the fish to emerge from the box. If the fish still had not emerged after $8 \mathrm{~min}$ we terminated the trial and allocated the fish a ceiling value of $480 \mathrm{~s}$. The exact number of fish tested at each site varied depending on the abundance of available test subjects, although we tested at least 20 females from every site. In total we tested 290 fish. Both males and females were tested; however, males were fairly uncommon because of a female-biased sex ratio at all sites (Table 1).

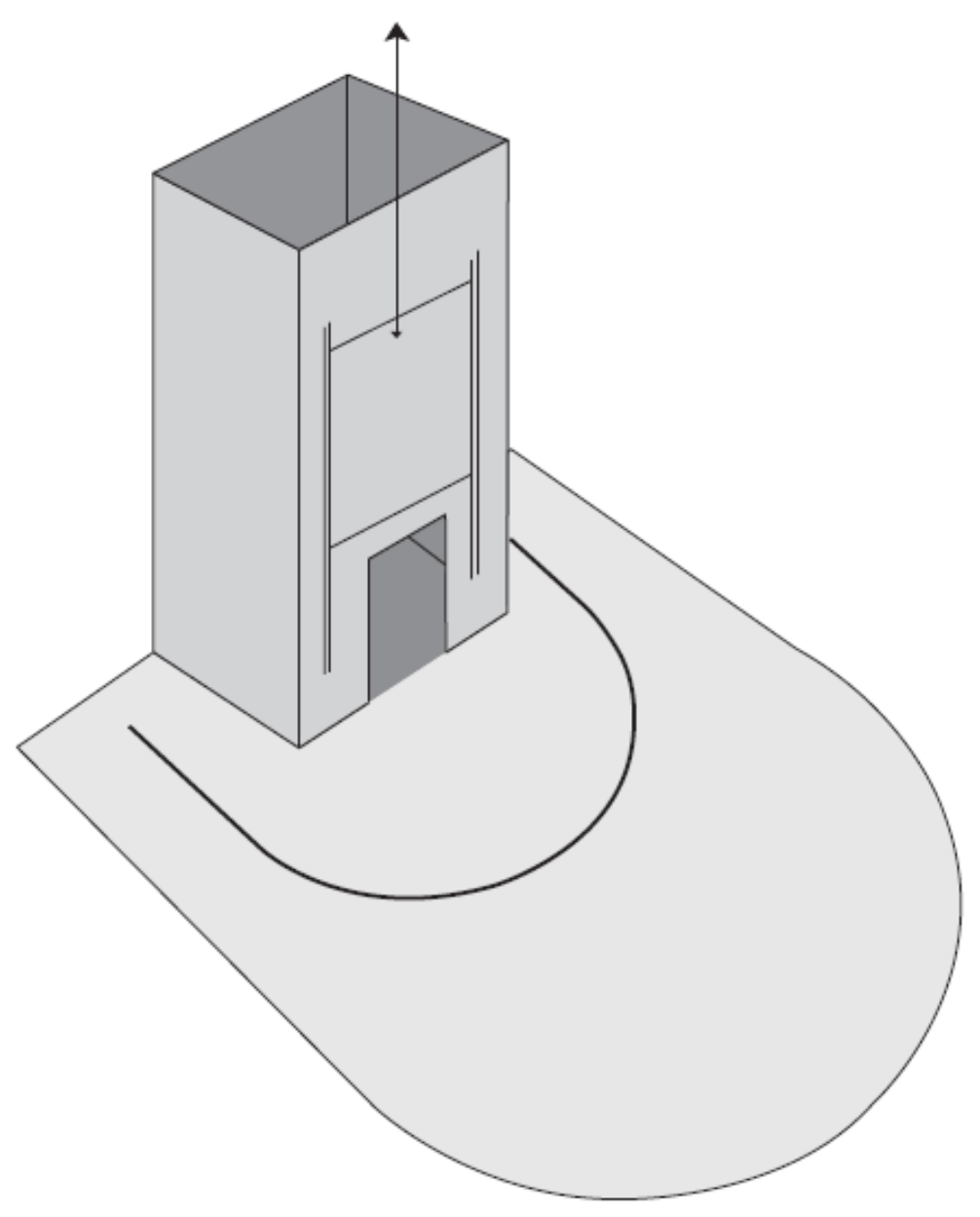

Figure 1. Diagram of the start box with the lid removed. Fish were placed in the box with a lid on top. After 2 min the trapdoor shown at the front of the box was raised and the fish were free to emerge. The hesitancy line (see text) is shown as a ring around the opening of the box. 
We defined the boldness score as the time taken for the fish's snout to emerge from the box. This test differs fundamentally from the open field arenas that have been used to examine boldness in various species (Waren \& Callaghan 1976; Fujita et al. 1994) in that the fish in this experiment were released into an environment with which they were totally familiar, and they were therefore aware of the risks involved in emerging from the chamber. The time to emerge from the chamber is highly correlated with other tests of boldness including the tendency to leave shoalmates and approach novel objects ( $\mathrm{C}$. Brown, unpublished data). Hesitancy was defined as the time the fish took to cross the black arc minus the time it took for the fish to emerge from the box. In the few instances where fish had not emerged by the end of 8 min no hesitancy score was calculated.

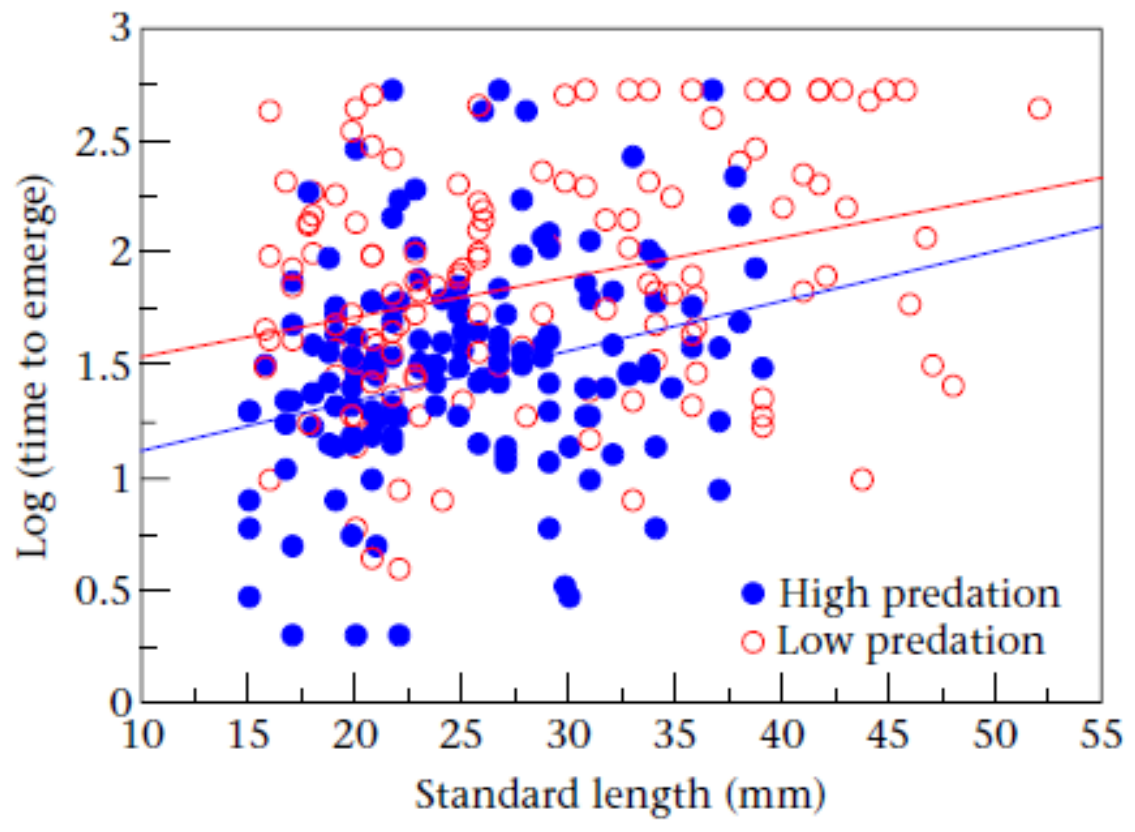

Figure 2. The relation between standard length and the time to emerge from the start box for fish from highand low-predation regions. Regression lines are shown for fish from low-predation (top line) and highpredation (bottom line) areas.

To investigate the affect of age/size on the tendency to emerge from the box, we conducted regression analyses on both hesitancy and boldness scores against standard length. We analysed standard length by ANOVA to determine whether there were differences between sites and sexes. Since a strong relation between boldness scores and standard length was apparent and the mean size of fish differed between collection sites, we then analysed the boldness data using ANCOVA with standard length as a covariate, and river, predator regime (high or low) and sex as fixed effects. The hesitancy data showed no relation with size and was analysed with an ANOVA. Both the hesitancy data and the boldness data were log transformed prior to analysis.

\section{Results}

Both males and females from upstream sites tended to be larger than those from downstream sites (ANOVA $\left.F_{1,274}=5.012, P=0.026\right)$. Males were smaller than females $\left(F_{1,274}=21.366, P<0.001\right.$ ), and there was no significant difference in the length of fish between rivers $\left(F_{3,274}=0.979, P=0.403\right)$. There were no significant interactions between any of the three factors. Females over $40 \mathrm{~mm}$ and males over 
$30 \mathrm{~mm}$ were never found in downstream locations. The data also suggest that upstream males mature later than downstream males since no upstream males smaller than $20 \mathrm{~mm}$ were collected.

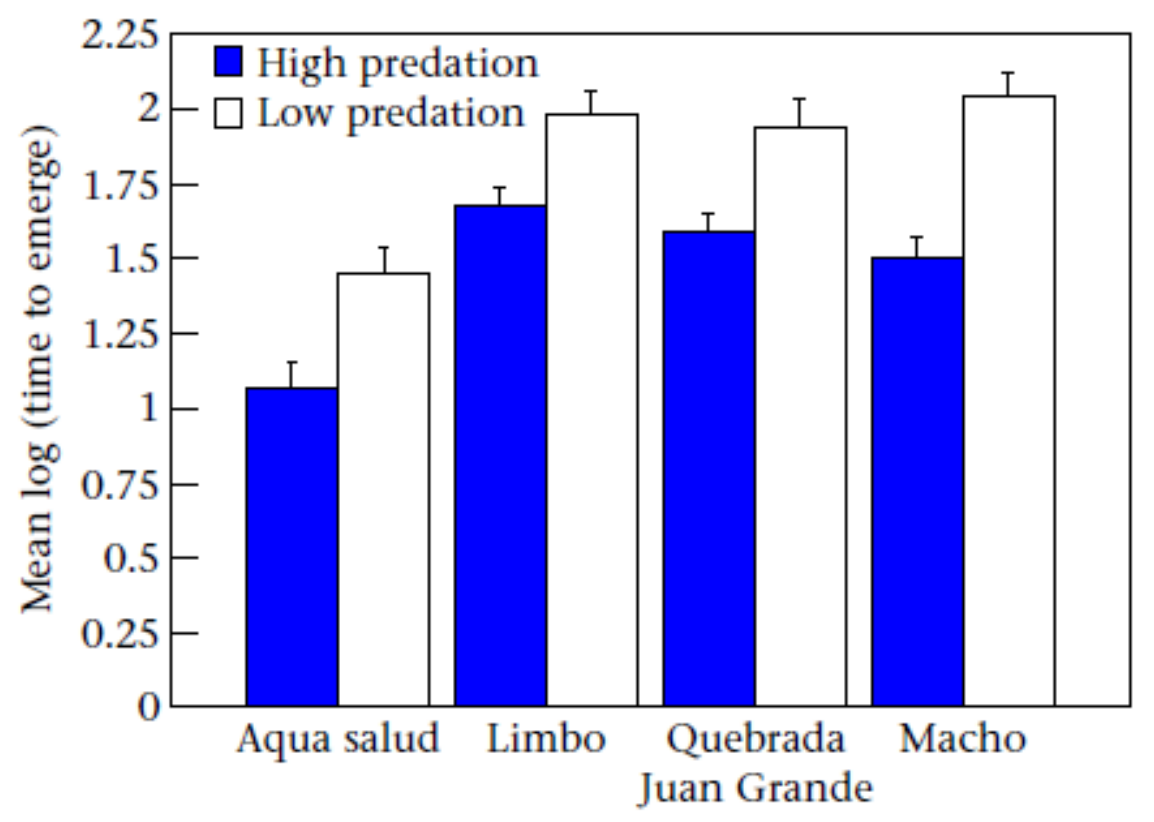

Figure 3. The mean + SE time to emerge from the start box for fish from high- and low-predation sites from each of the four rivers.

Our analysis revealed a strong correlation between standard length and boldness $\left(F_{1,288}=35.25, P<\right.$ 0.001) with small fish emerging from the box sooner than larger fish (Fig. 2). A test of parallelism showed that this relation did not vary between regions of high- and low-predation pressure $\left(F_{1,272}=0.176, P<\right.$ $0.675)$, between rivers $\left(F_{3,270}=1.853, P<0.138\right)$ or between sexes $\left(F_{1,272}=1.665, P<0.198\right)$. Further analysis of the boldness data using ANCOVA showed large differences between the four rivers in the mean time to emerge $\left(F_{3,273}=15.37, P<0.001\right)$, as well as differences between the high- and lowpredation sites $\left(F_{1,273}=21.878, P<0.001\right)$. Post hoc analysis (Fisher's partial least squares difference, PLSD) revealed that fish from Aqua Salud emerged more quickly than fish from the other three rivers. Contrary to our expectations, fish from high-predation sites were significantly bolder than low-predation fish (Fig. 3). There was no significant interaction between river and predator regime $\left(F_{1,273}=1.789, P<\right.$ $0.149)$, nor was there a significant difference between the sexes $\left(F_{1,273}=0.505, P=0.478\right)$. Post hoc analysis (Fisher's PLSD) revealed significant differences between high- and low-predation areas in all rivers $(P<0.003)$. The hesitancy score showed no relation with size and an ANOVA confirmed differences between rivers $\left(F_{3,251}=14.654, P<0.001\right)$ and between sites $\left(F_{1,251}=7.712, P=0.008\right)$ similar to those in the boldness data, as well as revealing differences between the sexes. Males showed less hesitation when crossing the white, plastic semicircle than females $\left(F_{1,251}=5.547, P=0.019\right)$. There were no significant interactions between any of the variables.

\section{Discussion}

Analysis of the boldness scores highlights the role of exposure to different environments in shaping population differences in temperament traits. First, there was a strong negative relation between boldness 
and standard length as predicted by the metabolic hypothesis and, importantly, this relation did not vary between upstream and downstream locations (Fig. 2). This suggests that metabolic requirements of small fish compel them to emerge from shelter sooner than larger fish and begin foraging regardless of the level of predation pressure. We obtained similar results in the laboratory (Brown \& Braithwaite 2004) suggesting that the result has little to do with the environment into which the fish were released. The existence of similar relation between body size and time to emerge in both upstream and downstream fish in this study dismisses the alternative explanation for heavy selection pressure against bold individuals, since this would presumably occur only under high-predation regimes. Thus, the difference in the propensity to take risks and emerge from cover early seems to diminish as the fish age. This result indicates that variation in metabolism may be one of the physiological mechanisms shaping personality traits.

Fish from high-predation areas were consistently bolder than those from low-predation sites. It is commonly thought that since predator-sympatric populations are more likely to respond to predators than predator-allopatric populations, they should be more cautious in the face of predation hazards (Seghers 1974; Pitcher \& Parrish 1993). Our results conflict with this theory and demonstrate that in fact the opposite is true. Fish from high-predation areas were far bolder than those from low-predation areas. Predator-sympatric fish still need to forage and reproduce just as their upstream counterparts do. To carry out these behaviours in the shadow of constant predation threat they must behave relatively boldly. Under such circumstances any fish that remains in hiding for extended periods is likely to show reduced fitness owing to lost foraging or mating opportunities (Lima \& Bednekoff 1999). Thus, in high-predation areas there is probably strong selection favouring bold individuals, whereas this selection force is lacking in lowpredation areas. Wilson et al. (1993) found substantial differences in the behaviour of bold and shy sunfish, Lepomis gibbosus. Bold fish adjusted to life in captivity 5 days earlier than shy sunfish. In addition, bold fish ate more copepods, had different parasite fauna and tended to forage further from shoalmates than shy fish. It is clear from Wilson et al.'s study and our own that variation in personality traits will have substantial influences on individual fitness in wild populations.

It may be argued that because the fish from all populations were released into different environments (into high- and low-predation areas) the boldness results may be influenced in some manner. However, fish released into low-predation regions ought to emerge from cover sooner than those released into highpredation areas, which is the opposite pattern to the results reported here. The differences between highand low-predation fish may also be the result of phylogeny (Johnson 2001); however, it is highly unlikely that all fish from high-predation areas are more closely related to one another than they are to their counterparts just above the waterfalls within the same river. Our data are further supported by laboratory study in which guppies and killifish, Rivulus hartii from high-predation regions were more tenacious (defined as the feeding rate in the presence of a predator divided by the feeding rate in the absence of a predator) than fish from low-predation regions (Fraser \& Gilliam 1987). Similarly, Iberian rock lizards, Lacerta monticola, exposed to simulated predation pressure also develop personality differences that are manifested in differential propensity to emerge from cover (Lopez et al. 2005). We conclude, therefore, that our results show that animals' temperaments become 'primed' for optimal responses within the context of the prevailing ecological conditions and animals appear to become increasingly shy as they grow within these constraints. Whether differentiation between upstream and downstream sites occurs over an evolutionary or ontogenetic timeframe remains to be seen and represents an area for future research.

One alternative explanation for the differences in the time to emerge from hiding is that motivation differs between the two populations. It could be that fish from high-predation areas are simply more hungry because they have limited access to prey items, owing to the presence of predators and heterospecific 
competitors. Future investigations could examine the correlation between body condition and boldness in the field or, alternatively, one could provide supplementary food before testing the fish. Further research could also be directed at identifying the underlying physiological or neuroendocrinological mechanisms that are driving the divergence in personality traits. For example, individuals may differ in how they respond to mild stressors, which may in turn affect their propensity to explore novel environments (Brown \& Braithwaite 2005).

While there were no significant differences between the sexes in the boldness score, males still tended to be faster to emerge than females, as we predicted. However, there were differences between the sexes in the degree of hesitation as the fish emerged from the shelter and entered the pool. Females hesitated for longer before crossing the white $D$ than males. It is likely that as soon as the males realized they could get back into the stream and chase females they did so, despite the danger of crossing the high-contrast background. There was no interaction with predation regime, suggesting that the 'single-mindedness' of the males' behaviour did not change in the presence or absence of predators. Similar observations have been made in juvenile brown trout, Salmo trutta, where males were less likely to respond to repeated predator attack than females and were more than twice as likely to instigate agonistic interactions (Johnsson et al. 2001). These differences in boldness between males and females are likely to have a hormonal basis. Much of the male mortality in these rivers probably results from females defending themselves from harassment, rather than directly from predators. Despite the dangers involved with courting females (the average female weighs 2.5 times the average male), bold males are rewarded with higher rates of insemination with increasing mating attempts (Evans et al. 2003). This notion that courtship is dangerous for males also ties in with our observation of decreasing numbers of males as the relative densities of $B$. episcopi increased and may also explain why males mature later and at larger sizes in low-predation locations. It is now well documented that differences in life history priorities result in differences in the behaviour of the sexes (Poecilia reticulata: Reznick et al. 2001; Brachyraphis rhabdophora: Reznick et al. 1993; Johnson 2001; B. episcopi: Jennions \& Telford 2002). Males maximize their fitness by inseminating as many females as possible, are preoccupied with chasing females and appear to live short, dangerous lives. Females, on the other hand, maximize fitness by increasing longevity and spend most of their time foraging. There is no better way to elucidate this difference in lifestyle than by examining the behaviour of poeciliids that are confronted with a predator. Females stop foraging, form shoals and fixate on the predator, whereas males make the most of the distraction by increasing attempts at sneaky mating (Reznick \& Endler 1981; Evans et al. 2003).

Finally, we found significant differences in the behavior of the fish between rivers. Aqua Salud fish were bolder than fish from the other three rivers (Fig. 3). This river is the most geographically isolated of the four rivers tested and, ironically, has the least difference in predation pressure between its two collecting sites (Table 1). Although we attempted to choose rivers and sites within rivers that were as similar as possible in terms of the physical and social environments, clearly no river is identical to another. This environmental variation from catchment to catchment evidently has a strong impact on the development of boldness traits that is of a similar magnitude to that explained by variation in predation pressure.

In conclusion, our results suggest that the temperaments of fish vary considerably with age, sex and the level of predation pressure in the environment indicating that temperaments may be more labile than previously suspected. One major difficulty remains, and that is distinguishing between short-term behavioural plasticity and long-term, stable psychological states and behavioural syndromes (Sih et al. 2004). This is particularly the case in short-lived animals and may be the single greatest obstacle when attempting to marry psychology with the behavioural ecology literature. Psychologists may point out that boldness-shyness and other personality traits are defined as long-term, stable psychological states. Nevertheless, the propensity to take risks and other behavioural traits are known to be heavily influenced 
by internal states, such as hunger, as well as demographic variables including age and sex, all of which may be influenced by body size (Wilson et al. 1994; Krause et al. 1998). This is also the case with human studies where sex, ethnicity, age and health status are all important variables when explaining personality differences (van Gestel \& van Broeckhoven 2003). The two notions may not necessarily be entirely incompatible, however, as long as the differences between individuals are maintained in a variety of contexts, while still allowing for a degree of short-term behavioural plasticity in response to internal or external environmental fluctuations (Sih et al. 2004). The study of animal personalities and their potential evolutionary consequences is still in its early stages. We still know little about the proximate and ultimate causes of interindividual behavioural variance in populations from an ecological and evolutionary perspective. Disentangling the relative roles of heritability, ecological and social forces that create and maintain personality traits, as well as identifying the underlying physiological and neuroendocrinological mechanisms responsible for these traits, remains a major challenge.

\section{Acknowledgments}

Our work was funded by NERC research grant \# (NER/A/S/01/00608) and was conducted under ANAM permit \# SEX/A-88-03. We thank the Smithsonian Tropical Research Institute, in particular Biff Birmingham, for their continuing cooperation and support. We also thank the anonymous referees for their helpful comments.

\section{References}

Brown, C. 2000. The behavioural ecology of predator avoidance in rainbowfish (Melanotaenia spp.). Ph.D. thesis, University of Queensland. http://geocities.com/culumbrown/thesis.

Brown, C. \& Braithwaite, V. A. 2004. Size matters: a test of boldness in eight populations of bishop, Brachyraphis episcopi. Animal Behaviour, 68, 1325-1329. doi:10.1016/j.anbehav.2004.04.004.

Brown, C. \& Braithwaite, V. A. 2005. Effects of predation pressure on the cognitive ability of the poeciliid Brachyraphis episcopi. Behavioral Ecology, 16, 482-497. doi:10.1093/beheco/ari 016.

Budaev, S. V. 1997. 'Personality' in the guppy (Poecilia reticulata): a correlational study of exploratory behavior and social tendency. Journal of Comparative Psychology, 111, 399-411.

Endler, J. A. 1995. Multiple trait coevolution and environmental gradients in guppies. Trends in Ecology and Evolution, 10, 22-29.

Evans, J. P., Pilastro, A. \& Ramnarine, I. W. 2003. Sperm transfer through forced matings and its evolutionary implications in natural guppy (Poecilia reticulata) populations. Biological Journal of the Linnaean Society, 78, 605-612. doi:10.1046/j.0024-4066.2002.00193.x.

Fraser, D. F. \& Gilliam, J. F. 1987. Feeding under predation hazard, response of the guppy and Hart's rivulus from sites with contrasting predation hazard. Behavioral Ecology and Sociobiology, 21, 203-209.

Fraser, D. F. \& Huntingford, F. A. 1986. Feeding and avoiding predation hazard: the behavioural response of prey. Ethology, 73, 57-68.

Fujita, O., Annen, Y. \& Kitaoka, A. 1994. Tsukuba high-emotional and low-emotional strains of rats (Rattus norvegicus): an overview. Behavior Genetics, 24, 389-415.

van Gestel, S. \& van Broeckhoven, C. 2003. Genetics of personality: are we making progress? Molecular Psychiatry, 8, 840-852. doi:10.1038/sj.mp.4001367.

Goddard, M. E. \& Bilharz, R. G. 1985. A multivariate analysis of the genetics of fearfulness in potential guide dogs. Behavior Genetics, 15, 69-89. 
Godin, J.-G. J. \& Smith, S. A. 1988. A fitness cost of foraging in the guppy. Nature, 333, 69-71.

Gosling, S. 2001. From mice to men: what we can learn about personality from animal research. Psychological Bulletin, 127, 45-86.

Griffiths, S. W. \& Magurran, A. E. 1998. Sex and schooling behaviour in the Trinidadian guppy. Animal Behaviour, 56, 689-693.

Jennions, M. D. \& Telford, S. R. 2002. Life-history phenotypes in populations of Brachyrhaphis episcopi (Poeciliidae) with different predator communities. Oecologia, 132, 44-50. doi:10.1007/s00442002-0942-4.

Johnson, J. B. 2001. Adaptive life-history evolution in the live-bearing fish Brachyrhaphis rhabdophora: genetic basis for parallel divergence in age and size at maturity and a test of predator-induced plasticity. Evolution, 55, 1486-1491.

Johnsson, J. I., Sernland, E. \& Blixt, M. 2001. Sex-specific aggression and antipredator behaviour in young brown trout. Ethology, 107, 587-599.

Kamil, A. C. \& Balda, R. P. 1990. Spatial memory in seed-caching corvids. Psychology of Learning and Motivation, 26, 1-25.

Krause, J., Loader, S. P., McDermott, J. \& Ruxton, G. D. 1998. Refuge use by fish as a function of body length-related metabolic expenditure and predation risks. Proceedings of the Royal Society of London, Series B, 265, 2373-2379. doi:10.1098/rspb.1998.0586.

Lima, S. L. 1998. Stress and decision making under the risk of predation: recent developments from behavioural, reproductive and ecological perspectives. Advances in the Study of Animal Behavior, 27, 215-290.

Lima, S. L. \& Bednekoff, P. A. 1999. Temporal variation in danger drives antipredator behavior: the predation risk allocation hypothesis. American Naturalist, 153, 649-659.

Lima, S. L. \& Dill, L. M. 1990. Behavioral decisions made under the risk of predation, a review and prospectus. Canadian Journal of Zoology, 68, 619-640.

Lopez, P., Hawlena, D., Polo, V., Amo, L. \& Martin, J. 2005. Sources of individual shy-bold variations in antipredator behavior of male Iberian rock lizards. Animal Behaviour, 69, 1-9. doi:10.1016/j.anbehav.2004.05.010.

Magurran, A. E. 1986. Predator inspection behaviour in minnow shoals: differences between populations and individuals. Behavioral Ecology and Sociobiology, 19, 267-273.

Pitcher, T. J. \& Parrish, J. 1993. The function of shoaling behaviour. In: The Behaviour of Teleost Fishes. 2nd edn. (Ed. by T. J. Pitcher), pp. 363-439. London: Chapman \& Hall.

Pitcher, T. J., Lang, S. H. \& Turner, J. A. 1988. A risk balancing trade off between foraging rewards and predation hazard in a shoaling fish. Behavioral Ecology and Sociobiology, 22, 225- 228.

Reznick, D. \& Endler, J. A. 1981. The impact of predation on life history evolution in Trinidadian guppies (Poecilia reticulata). Evolution, 36, 160-177.

Reznick, D., Meyer, A. \& Frear, D. 1993. Life-history of Brachyraphis rhabdophora (Pisces: Poeciliidae). Copeia, 1, 103-111.

Reznick, D., Butler, M. J. \& Rodd, H. 2001. Life-history evolution in guppies. VII. The comparative ecology of high- and low-predation environments. American Naturalist, 157, 126-140.

Seghers, B. 1974. Schooling behaviour in the guppy (Poecilia reticulata), an evolutionary response to predation. Evolution, 28, 486-489.

Sih, A. 1980. Optimal behaviour: can foragers balance two conflicting demands? Science, 210, 10411043.

Sih, A., Bell, A. \& Johnson, J. C. 2004. Behavioral syndromes: an ecological and evolutionary overview. Trends in Ecology and Evolution, 19, 372-378. doi:10.1016/j.tree.2004.04.009.

Skalski, G. T. \& Gilliam, J. F. 2002. Feeding under predation hazard: testing models of adaptive behavior with stream fish. American Naturalist, 160, 158-172. doi:10.1086/341012. 
Sogard, S. M. 1997. Size selective mortality in the juvenile stage of teleost fishes: a review. Bulletin of Marine Science, 60, 1129-1157.

Waren, E. W. \& Callaghan, S. 1976. Individual differences in response to an open field test by the guppy, Poecilia reticulate (Peters). Journal of Fish Biology, 18, 499-513.

Werner, E. E. \& Anholt, B. R. 1993. Ecological trade-off between growth and mortality rates mediated by foraging activity. American Naturalist, 142, 242-272.

Wilson, D. S., Coleman, K., Clark, A. B. \& Biederman, L. 1993. Shy-bold continuum in pumpkinseed sunfish (Lepomis gibbosus): an ecological study of a psychological trait. Journal of Comparative Psychology, 107, 250-260.

Wilson, D. S., Clark, A. B., Coleman, K. \& Dearstyne, T. 1994. Shyness and boldness in humans and other animals. Trends in Ecology and Evolution, 9, 442-446. doi:10.1016/0169-5347(94)90134-1.

Wootton, R. J. 1994. Energy allocation in the threespine stickleback. In: The Evolutionary Biology of the Three-spined Stickleback (Ed. by A. Belt \& S. A. Foster), pp. 250-260. Oxford: Oxford University Press. 